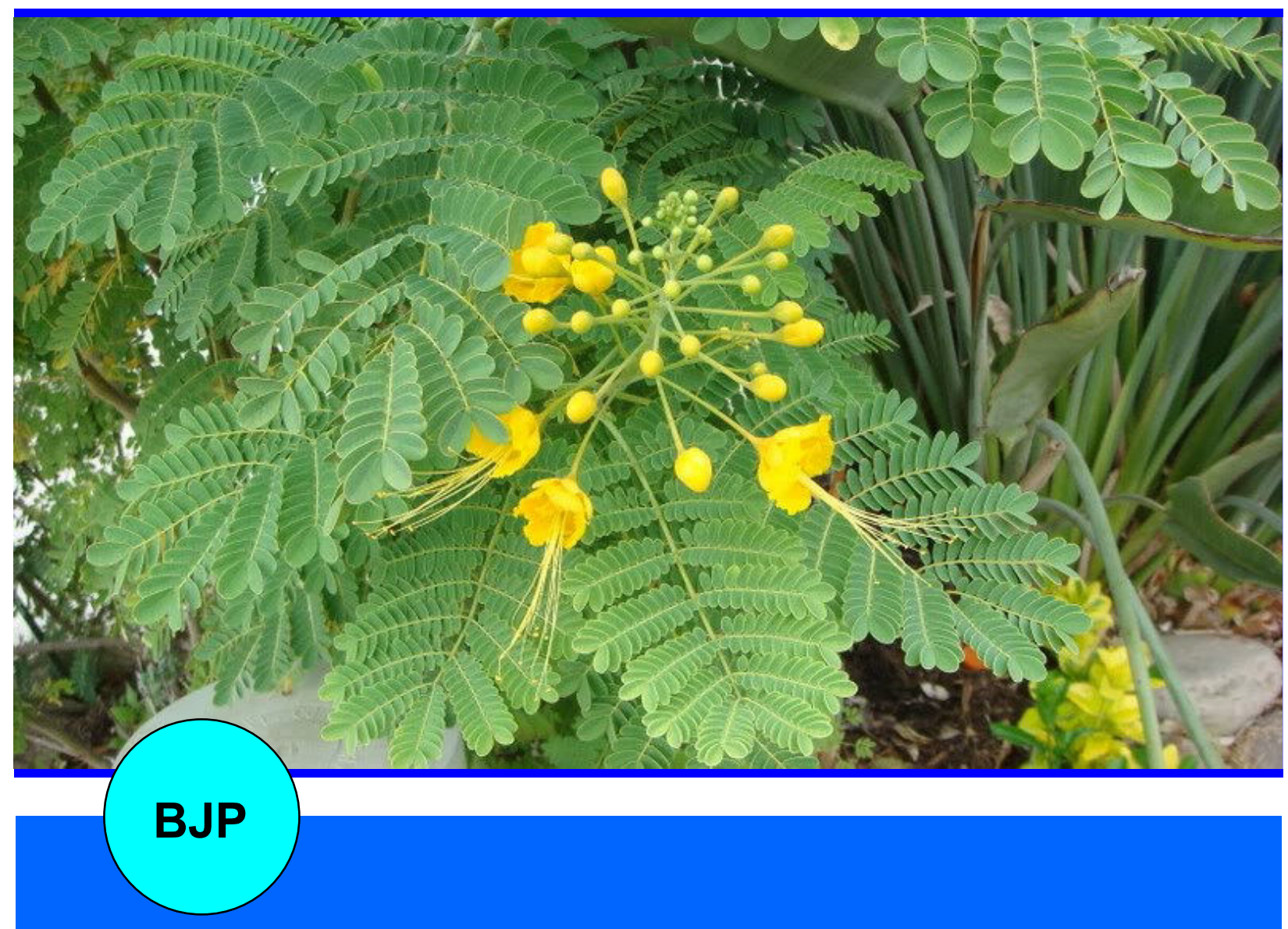

Bangladesh Journal of Pharmacology

Research Article

Antimalarial efficacy of nine medicinal plants traditionally used by the Karens of Andaman and Nicobar Islands, India 
Abstracted/indexed in Academic Search Complete, Asia Journals Online, Bangladesh Journals Online, Biological Abstracts, BIOSIS Previews, CAB Abstracts, Current Abstracts, Directory of Open Access Journals, EMBASE/Excerpta Medica, Google Scholar, HINARI (WHO), International Pharmaceutical Abstracts, Open J-gate, Science Citation Index Expanded, SCOPUS and Social Sciences Citation Index;

ISSN: $1991-0088$

\title{
Antimalarial efficacy of nine medicinal plants traditionally used by the Karens of Andaman and Nicobar Islands, India
}

\author{
M. Punnam Chander ${ }^{1}$, C. R. Pillai ${ }^{2}$ and P. Vijayachari ${ }^{1}$ \\ ${ }^{1}$ Regional Medical Research Centre (Indian Council of Medical Research), WHO Collaborating Centre for \\ Diagnosis, Reference, Research and Training in Leptospirosis, Port Blair 744 101, Andaman and Nicobar Islands, \\ India; ${ }^{2}$ National Institute of Malaria Research (Indian Council of Medical Research), New Delhi, India.
}

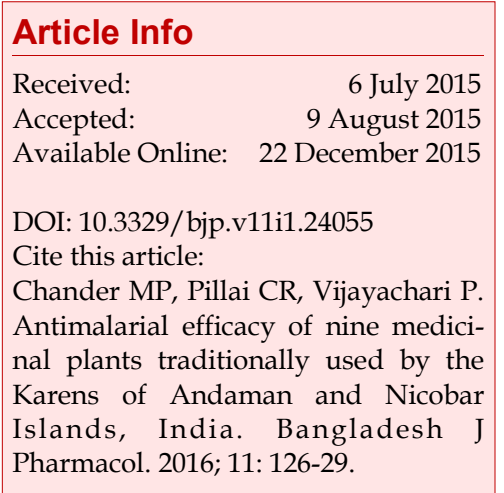

\begin{abstract}
The aim of this study was to assess the antimalarial activity of nine medicinal plants used by Karens of Andaman and Nicobar Islands, against Plasmodium falciparum chloroquine-sensitive MRC-2 isolate. The methanol extracts were obtained by cold percolation method and in vitro antimalarial activity was assessed using M-III method. The results indicated that out of nine plant species tested, four plants, viz., Z. spectabilis, S. wallichiana, C. pulcherrima and Amomum sp. demonstrated significant antimalarial activity $(50 \%$ inhibitory concentration values were $5.5 \pm 0.7,12.0 \pm 2.5,14.6 \pm 1.3$ and $37.3 \pm 2.5 \mu \mathrm{g} / \mathrm{mL}$ respectively) with no toxicity effect on erythrocytes.
\end{abstract}

\section{Introduction}

Andaman and Nicobar Islands, a union territory of India, has been historically known for high malaria transmission. The tropical climate prevailing throughout the year provides an ideal environment for mosquito proliferation and breeding in Nicobar group of islands (Manimunda et al., 2011). Entire land mass in the island has a network of creeks which results in ideal brackish water habitats for the breeding of Anopheles sundaicus, the predominant vector of malaria in Andaman and Nicobar Islands (Krishnamoorthy et al., 2005).

Malaria prevalence has increased alarmingly in past few years due to the development of drug resistance by Plasmodium falciparum (Parzy et al., 1997). Therefore, new and more effective therapeutic agents are urgently required to overcome the problem of malaria.

The Karen tribe is a lesser-known community in these Islands, settled in Mayabunder, North and Middle Andaman District. Karen derives from the word 'Kavin' as British called them, while they called themselves as
Pwakanyaw, the quiet and easy going people, hailing from Henzada, Pathe and Nachaon areas of Pegu district in Western Myanmar (Oberai, 2000). Presently they inhabit three villages depending on agriculture and fishing for livelihood. Most of them depend on traditional medicine, though modern medicine had increased rapidly during recent times (Chander et al., 2015). As a part of the ongoing studies documented their traditional treatment practices and collected plants which were reported to be efficacious in the treatment of traditional medicine system.

In the present study, nine of these plants were subjected to in vitro antimalarial activity against $P$. falciparum chloroquine-sensitive (MRC-2) isolate.

\section{Materials and Methods}

\section{Plant materials}

Nine plants were selected for evaluation on the basis of their ethnomedicinal histories. The names of these 
Table I

Antimalarial activity of ethnomedicinal plant used by Karens of Andaman and Nicobar Islands

\begin{tabular}{|lllc|}
\hline Scientific name (Voucher No.) & Family & Local Name & \multicolumn{1}{c}{$\begin{array}{c}\text { Antimalarial activity } \\
\mathrm{IC}_{50}(\mu \mathrm{g} / \mathrm{mL})\end{array}$} \\
\hline $\begin{array}{l}\text { Amomum spp. (AN-509) } \\
\text { Boesenbergia rotunda } \text { (L.) Mansf. (AN-505) }\end{array}$ & Zingiberaceae & Thajokha & $37.3 \pm 2.5$ \\
Caesalpinia pulcherrima (L.) Sw. (AN-521) & Caesalpiniaceae & Posibo & $>100.00$ \\
$\begin{array}{l}\text { Cinnamomum tamala } \text { (Buch.-Ham.) T. Nees \& } \\
\text { Eberm. (AN-524) }\end{array}$ & Lauraceae & Thechipogow & $14.6 \pm 1.3$ \\
Moringa oleifera Lam. (AN-512) & Moringaceae & Dandloadaw & $>100.0$ \\
Senna alata (L.) Roxb. (AN-502) & Caesalpiniaceae & Katheepaw & $>100.0$ \\
Solanum torvum Sw. (AN-522) & Solanaceae & Takotako & $>100.0$ \\
Strychnos wallichiana Steud. ex DC. (AN-511) & Loganiaceae & Niveka & $>100.0$ \\
Zingiber spectabilis Griffith (AN-503) & Zingiberaceae & Methalow & $12.0 \pm 2.5$ \\
Choloroquionine & & & $5.5 \pm 0.7$ \\
\hline
\end{tabular}

$\mathrm{IC}_{50}$ values are expressed as a mean of three independent values and were recorded in $\mu \mathrm{g} / \mathrm{mL}$

plants in alphabetical order, with their respective scientific name, voucher numbers, family and vernacular name (Karen language) are presented in the Table I. Plant materials were collected in the three villages of Mayabunder, North and Middle Andaman District along with Traditional Knowledge Providers (TKPs) and authenticated by the plant taxonomist at the Botanical Survey of India, Andaman and Nicobar Islands, where voucher specimens were deposited in the Medicinal plant laboratory at the Regional Medical Research Centre (ICMR), Port Blair.

\section{Extraction preparation}

The plants were washed, shade dried at room temperature and ground into a fine powder. One hundred gram of each plant powder was subjected to percolation by soaking in $95 \%$ methanol. After 7 days of dark incubation, the filtrate was concentrated separately by rotary vacuum evaporation $\left(45^{\circ} \mathrm{C}\right)$. Stock solutions of crude extracts were made in dimethyl sulfoxide (DMSO).

\section{Parasite cultivation}

The antimalarial activity of plant extracts was assessed against chloroquine-sensitive $P$. falciparum (MRC-2) isolate obtained from the National Institute of Malaria Research (ICMR), New Delhi, India. P. falciparum is cultivated in human $\mathrm{A} \mathrm{Rh}^{+}$red blood cells using RPMI 1640 medium (Sigma, India) supplemented with AB $\mathrm{Rh}^{+}$serum $(10 \%), 5 \%$ sodium bicarbonate (Sigma, India) and $40 \mu \mathrm{g} / \mathrm{mL}$ of gentamicin sulfate (Sigma, India) (Trager and Jensen, 1976).

\section{In vitro test for antimalarial activity}

The in vitro activity of $P$. falciparum intraerythrocytic stage on crude plant extracts was evaluated by Schizont maturation Inhibition M-III method (WHO, 2001). Briefly, crude extracts were dissolved in DMSO and serially diluted with RPMI 1640 medium to reach 1 $\mathrm{mg} / \mathrm{mL}$ before use. Serial double dilutions were made in 96-well microtiter plates (in triplicate) with a concentration range of $1.56-100 \mu \mathrm{g} / \mathrm{mL}$. The cultures, before testing, were synchronized by treatment with $5 \%$ D-sorbitol with a parasitemia of $0.6-0.8 \%$. Each well received $10 \mu \mathrm{L}$ of parasite-infected erythrocytes, 5\% hematocrit and $90 \mu \mathrm{L}$ of different drug dilutions. Chloroquine and solvent controls contained similar concentrations of solvent, as that of test wells. The plates were incubated at $37^{\circ} \mathrm{C}$ for 24 hours. After confirmation of the presence of $10 \%$ mature schizonts in control wells (without drug), the blood from each well was harvested, and a thick film was prepared on a glass slide. The blood films were stained for $40 \mathrm{~min}$ with Giemsa stain at a dilution of $10 \%$ in double distilled water. Three independent optical-microscopy readings of the number of schizonts with three of more nuclei were carried out in 200 parasitized red blood cells for each dilution and duplicate. Growth inhibition was expressed as the percentage of schizonts in each concentration, compared with controls.

\section{Antimalarial activity calculation and analysis}

The number of schizonts observed per well was directly entered into the nonlinear regression software, HN- 
NonLin V 1.1, which was specific for the analysis of in vitro drug sensitivity assay for malaria. Individual dose response curves were generated and their $\mathrm{IC}_{50}$ values were determined.

\section{Chemical injury to erythrocytes}

In order to determine the possibility of chemical injury to the erythrocytes due to the extract, $100 \mu \mathrm{L}$ of $5 \%$ erythrocytes were incubated with $100 \mu \mathrm{L} / \mathrm{mL}$ of the extract at a dose equal to the highest used in the antimalarial assay. During the experiment, the conditions were maintained as in the case of antimalarial assay. After 24 hours of incubation, thin blood smears were stained with Giemsa and observed microscopically for any morphological changes. The morphological findings were compared with those of erythrocytes which are not exposed to the extract.

\section{Results}

The leaf extract of Z. spectabilis $\left(\mathrm{IC}_{50} 5.5 \pm 0.7 \mu \mathrm{g} / \mathrm{mL}\right.$ ) showed excellent antimalarial activity followed by extracts of $S$. wallichiana $\left(\mathrm{IC}_{50} 12.0 \pm 2.5 \mu \mathrm{g} / \mathrm{mL}\right), \mathrm{C}$. pulcherrima ( $\mathrm{IC}_{50} 14.6 \pm 1.3 \mu \mathrm{g} / \mathrm{mL}$ ) and Amomum sp. $\left(\mathrm{IC}_{50} 37.3 \pm 2.5 \mu \mathrm{g} / \mathrm{mL}\right)$. Moreover, the leaf extract of $C$. tamala, S. toroum, M. oleifera, S. alata and B. rotunda were relatively inactive with $\mathrm{IC}_{50}$ values higher than $100 \mu \mathrm{g} /$ $\mathrm{mL}$ (Table I).

The microscopic observation of uninfected erythrocytes incubated with the methanol extracts and uninfected erythrocytes from the blank column of the 96-well plate showed no morphological differences after 48 hours of incubation.

\section{Discussion}

In the early studies, we reported the list of plants used by the Karens for various illnesses (Chander et al., 2015) and we selected nine plants routinely used by the karens. Methanol extracts of Z. spectabilis, S. wallichiana and $C$. pulcherrima showed the antimalarial activity and no previous reports available on the antimalarial properties of these medicinal plants in the literature. A previous phytochemical investigation on non-volatile constituents of the rhizomes of $Z$. spectabilis afforded several flavonoids, terpenoids and also demonstrated the antibacterial activity (Sivasothyu et al., 2012). In the present study, the leaf extract of $Z$. spectabilis showed high antimalarial activity in crude form.

According to Rasaonaivo et al. (1992), an extract is very active if $\mathrm{IC}_{50}<5 \mu \mathrm{g} / \mathrm{mL}$, active $5 \mu \mathrm{g} / \mathrm{mL}<\mathrm{IC}_{50}<50 \mu \mathrm{g} / \mathrm{mL}$, weakly active $50 \mu \mathrm{g} / \mathrm{mL}<\mathrm{IC}_{50}<100 \mu \mathrm{g} / \mathrm{mL}$ and inactive $\mathrm{IC}_{50}>100 \mu \mathrm{g} / \mathrm{mL}$.

S. wallichiana is specifically used for malaria fever in Karen community and it showed good antimalarial activity. In previous reports, the presence of various phytochemical and antimicrobial activities of $S$. wallichiana was demonstrated (Mallikharjuna et al., 2010). Vivek et al. (2013) reported the antimicrobial and anti-oxidant properties of leaf and flower extracts of C. pulcherrima. In the present study, leaf extract showed the active antimalarial property.

The in vitro antimalarial activity might be due to the presence of alkaloids, flavonoids, triterpenes, sterols, tannins and saponins in the methanol extracts of tested plants. The mechanism of action might be due to the inhibition of hemozoin biocrystallization, inhibition of protein synthesis, decreased mitochondrial membrane potential and DNA fragmentation (Dubar et al., 2011; Lopez et al., 2010).

\section{Conclusion}

The methanol leaf extracts of Z. spectabilis, S. wallichiana and C. pulcherrima possess significant suppressive effects on in vitro cultures of chloroquine-sensitive $P$. falciparum. These plants could serve as useful sources for new antimicrobial agents.

\section{Conflict of Interest}

The authors have declared that there is no conflict of interest.

\section{Acknowledgement}

The authors acknowledge to the Indian Council of Medical Research (ICMR), New Delhi, India for providing financial grant for the study (Project No. Tribal/43/2008-ECD-II). Authors are also thankful to Botanical Survey of India, Port Blair for their help in identification of plant specimens.

\section{References}

Chander MP, Kartick C, Vijayachari P. Ethnomedicinal knowledge among Karens of Andaman \& Nicobar Islands, India. J Ethnopharmacol. 2015; 162: 127-33.

Dubar F, Egan TJ, Pradines B, Kuter D, Ncokazi KK, Forge D, Paul JF, Pierrot C, Kalamou H, Khalife J, Buisine E, Rogier C, Vezin H, Forfar I, Slomianny C, Trivelli X, Kapishnikov S, Leiserowitz L, Dive D, Biot C. The antimalarial ferroquine: Role of the metal and intramolecular hydrogen bond in activity and resistance. ACS Chem Biol. 2011; 6: 275-87.

Krishnamoorthy K, Purushothaman J, Natarajan R, Shriram AN, Pradeep KD, Sehgal SC. Altered environment and risk of malaria outbreak in South Andaman, Andaman \& Nicobar Islands, India affected by tsunami disaster. Malaria J. 2005; 4: 32.

Lopez ML, Vommaro R, Zalis M, De Souza W, Blair S, Segura C. Induction of cell death on Plasmodium falcciparum asexual blood stages by Solanum nudum steriods. Parasitol Int. 2010; 
59: $217-25$.

Mallikharjuna PB, Seetharam YN, Radhamma MN. Phytochemical and antimicrobial studies of Strychnos wallichiana Steud Ex DC. J Phytol. 2010; 2: 22-27.

Manimunda SP, Sugunan AP, Sha WA, Singh SS, Shriram AN, Vijayachari P. Tsunami, post-tsunami malaria situation in Nancowry group of islands, Nicobar district, Andaman and Nicobar Islands. Indian J Med Res. 2011; 133: 76-82.

Oberoi CP. Eco-tourism paradise: Andaman and Nicobar Islands. Delhi, B.R. Publishing Corporation, 2000.

Parzy D, Doerig C, Pradines B, Rico A, Fusai T, Doury JC. Proguanil resistance in Plasmodium falciparum African isolates: Assessment by mutation-specific polymerase chain reaction and in vitro susceptibility testing. Am J Trop Med Hyg. 1997; 57: 646-50.

Rasoanaivo P, Ratsimamanga US, Ramanitrhasimbola D,
Rafatro H, Rakoto RA. Criblage d' extraits de plantes de madagascar pour recherche $\mathrm{d}^{\prime}$ activite antipaludique et $\mathrm{d}^{\prime}$ effet potentialisateur de la chlorquine. J Ethnopharmcol. 1992; 64: 117-26.

Sivasothyu Y, Awangu K, Ibrahim H, Thong KL, Fitrah N, Koh $X P$ Tan LK. Chemical composition and antibacterial activities of essential oils from Zingiber spectabile Griff.J Essential Oil Res. 2012; 24: 305-13.

Trager W, Jensen JB. Human malaria parasites in continuous culture. Science 1976; 193: 673-75.

Vivek MN, Sachidananda Swamy HC, Manasa M, Pallavi S, Yashoda K, Asha MM, Chaithra M, PrashithKekuda TR, Mallikarjun N, Onkarappa R. Antimicrobial and antioxidant activity of leaf and flower extract of Caesalpinia pulcherrima, Delonix regia and Peltaphorum ferrugineum. J Appl Pharma Sci. 2013; 3: 64-71.

WHO. WHO/CTD/MAL/97 20 Rev 2, Geneva, 2001.

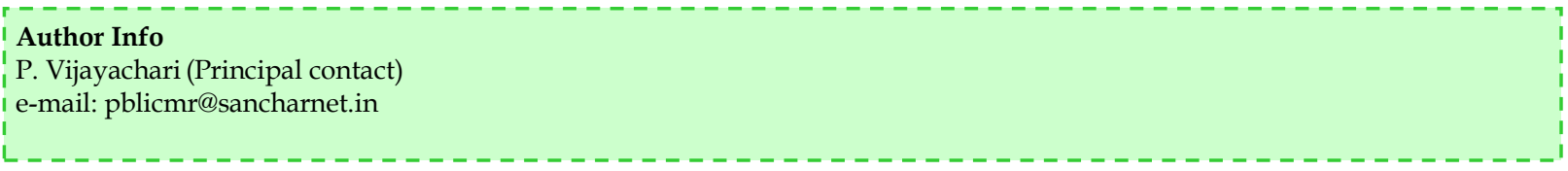

Author Info 


\section{Your feedback about this paper}

1. Number of times you have read this paper 0

2. Quality of paper Click

3. Your comments

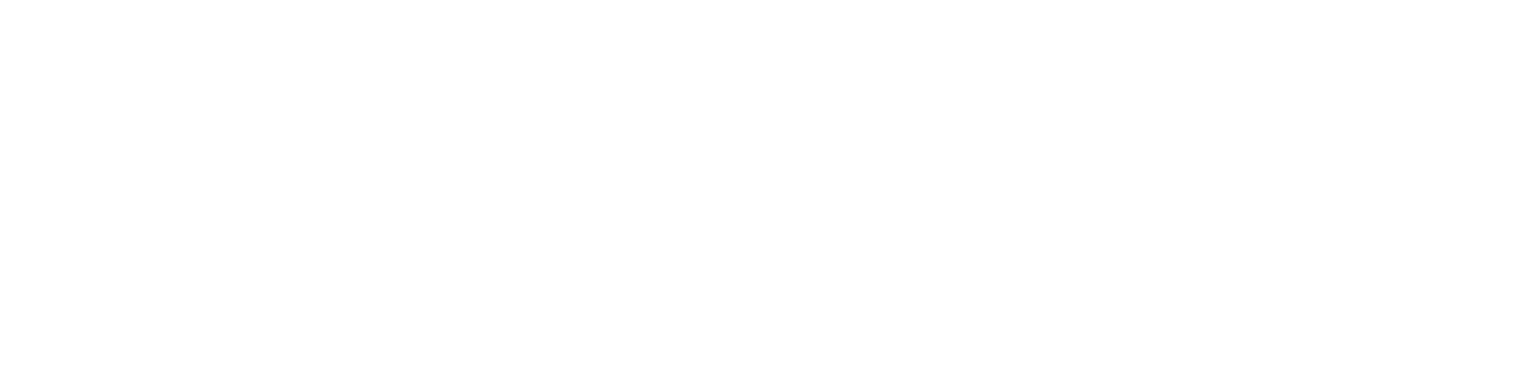

